\title{
Tracer Gas Techniques for Studying Building Air Exchange
}

Andrew K. Persily

U.S. DEPARTMENT OF COMMERCE

National Bureau of Standards

Center for Building Technology

Gaithersburg, MD 20899

February 1988

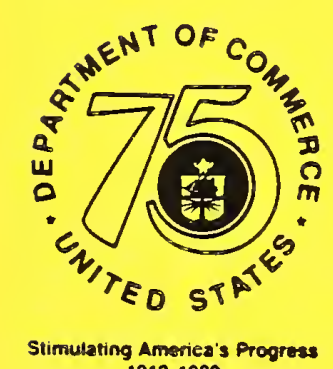

1913-1989
Ameriea's

U.S. DEPARTMENT OF COMMERCE

NATIONAL BUREAU OF STANDARDS 


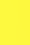


NBSIR 88-3708

\section{TRACER GAS TECHNIQUES FOR STUDYING BUILDING AIR EXCHANGE}

Andrew K. Persily

U.S. DEPARTMENT OF COMMERCE

National Bureau of Standards

Center for Building Technology

Gaithersburg, MD 20899

February 1988

U.S. DEPARTMENT OF COMMERCE, C. William Verity, Secretary NATIONAL BUREAU OF STANDARDS, Ernest Ambler, Director 
- 
A variety of procedures have been developed that employ tracer gases to study the air exchange characteristics of buildings. These procedures enable the examination of several features of building air exchange including ventilation rates, air movement within buildings, and building envelope airtightness. This paper reviews tracer gas measurement techniques that have been used to study air exchange in buildings. Background information is discussed such as the instrumentation used in these tests, building features that influence their application, and the fundamental theory of tracer gas measurement. Several specific applications are discussed including air exchange rate measurement in large buildings, low-cost procedures for measuring air exchange rates in large numbers of buildings, techniques for evaluating the performance of air distribution systems, and pressurization testing of envelope airtightness in large buildings. A detailed bibliography is also included to facilitate a more thorough examination of the topics discussed.

Key Words: airflow measurement; building performance; infiltration; measurement; tracer gas; ventilation. 


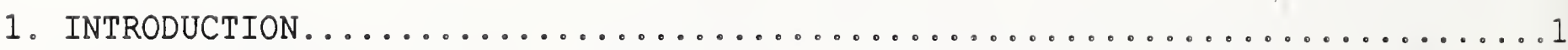

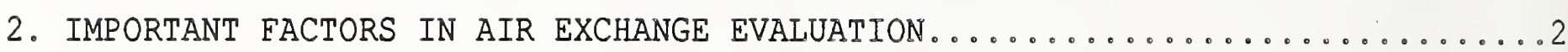

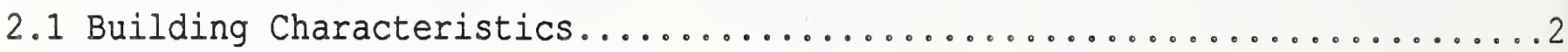

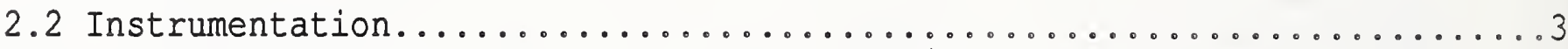

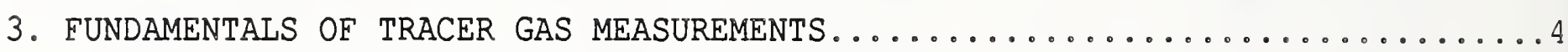

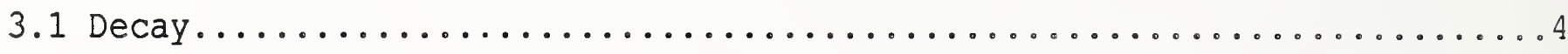

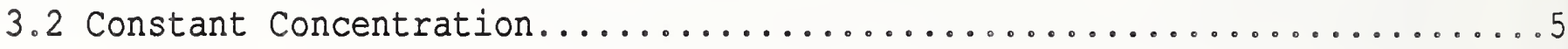

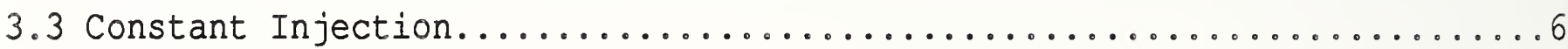

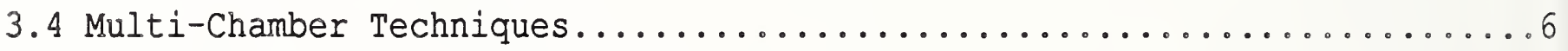

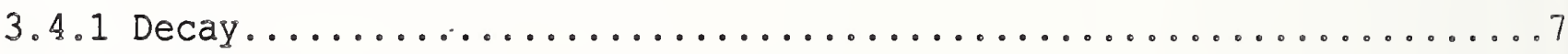

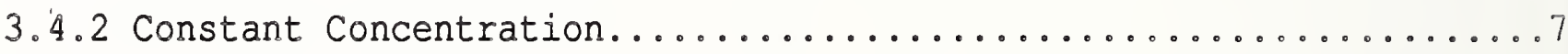

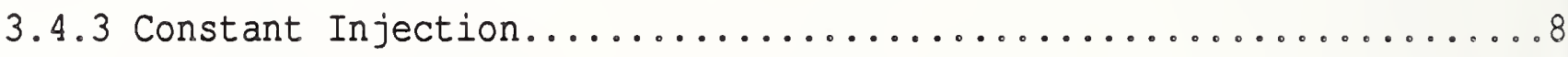

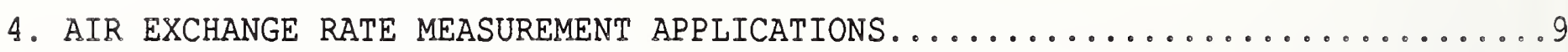

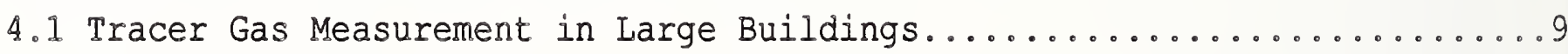

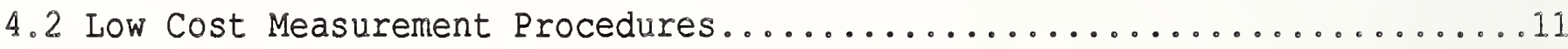

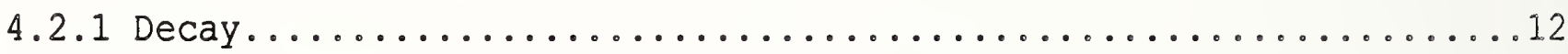

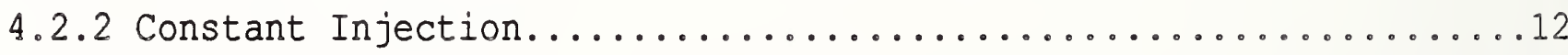

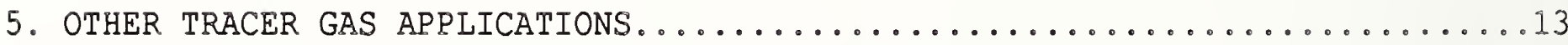

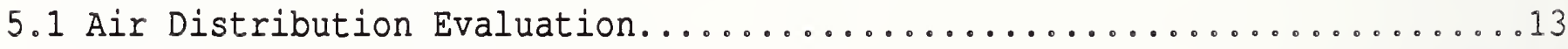

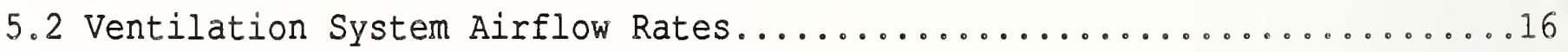

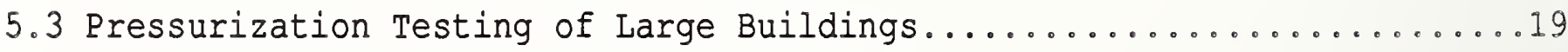

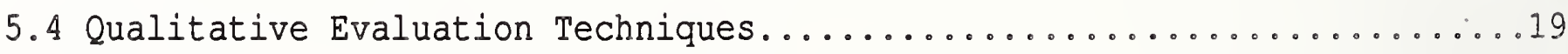

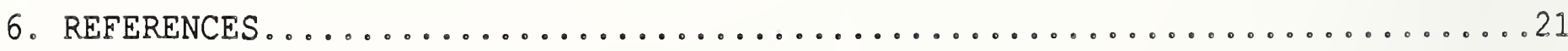




\section{INTRODUCTION}

This paper reviews tracer gas measurement techniques for studying air exchange in buildings. These techniques are used to examine three basic aspects of building air exchange including air exchange rates, interior air movement, and building envelope airtightness. There are numerous motivations for investigating these three aspects of building air exchange. The measurement of building air exchange rates is important as these rates relate to energy consumption and indoor air quality. Their measurement is useful for determining whether the outdoor air intake rate is compatible with design specifications, and whether relevant ventilation standards are being complied with. Tracer gases can also be used to examine interior air movement patterns, which are important as they relate to thermal comfort within the occupied space. These interior air movement measurement procedures can also be used to evaluate the performance of a building's air distribution system in providing ventilation air to the occupants and removing internally generated contaminants. Finally, these tracer gas procedures can be used to verify the isolation of special-use spaces, where hazardous substances are in use, from the rest of a building's interior.

The third area of building air exchange appropriate to tracer gas measurement is the determination of the airtightness of a building's envelope. Envelope airtightness is important as it relates to energy consumption due to uncontrolled air infiltration through the building shell. The existence of such infiltration influences interior thermal comfort due to drafts, and may lead to material, and possibly structural, damage to the building envelope due to moisture condensation. Air infiltration due to envelope leakage is often a significant fraction of the total building air exchange rate and therefore is important in understanding the indoor air quality of a building. Finally, the airtightness of the building envelope interacts with a building's mechanical ventilation system, affecting its ability to control air exchange rates and air distribution.

While there have been previous reviews of tracer gas measurement techniques (Alexander et al 1980; Harrje et al 1981 and 1982; Hitchin and Wilson 1967; Hunt 1980; Lagus 1980; Sherman et al 1980), this paper concentrates on more recent developments such as the study of large buildings, evaluations of air distribution effectiveness, and multi-tracer and multi-chamber techniques. The first section of this review discusses several of the basic issues related to evaluating building air exchange using tracer gases such as relevant building characteristics and tracer gas instrumentation. The second section provides a discussion of the fundamentals of tracer gas measurement including the mass balance theory on which the measurements are based and the three basic approaches, i.e. decay, constant concentration and constant injection. Multichamber and multi-tracer theory and applications are also discussed. The third section presents two applications of air exchange rate measurement procedures including measurements in large buildings and low-cost procedures that are useful for air exchange measurements in large numbers of buildings. The fourth and final section discusses other tracer gas applications including the evaluation of air distribution effectiveness, measurement of airflows within ventilation systems, pressurization testing of large buildings, and qualitative tracer gas evaluation techniques. 
In conducting a tracer gas evaluation of air exchange in any building there are several issues that must be considered. These include the characteristics of the building being studied and the instrumentation that will be used in the investigation. This section discusses these issues. In addition, there are some questions of terminology that need to be addressed at this stage. In this paper the term infiltration refers to uncontrolled air leakage into a building through unintentional openings in the building envelope, i.e., leaks, due to pressure differences across these openings. These pressure differences are caused by weather effects, wind and temperature differences between indoors and outdoors, as well as by mechanical equipment operation, both fans and combustion appliances. Exfiltration refers to airflow out of the building through these same leaks. The term ventilation refers to intentional outdoor air intake through a ventilation system, with mechanical ventilation being that ventilation induced by a mechanical system. Natural ventilation is unpowered airflow through intentional openings such as open windows and vents. The term air exchange rate refers to the total airflow into a building due to all of these processes, and in general they are all important in determining the net air exchange rate of a building. In many buildings, particularly residential, there is no mechanical ventilation except for bath and kitchen exhaust fans, and all the air exchange is due to infiltration and natural ventilation.

\subsection{Building Characteristics}

In order to apply any tracer gas evaluation procedure to a building one must consider several features of that particular structure in order to determine exactly what questions to ask about the building and how to conduct the measurements. It is very important to examine the building plans, the mechanical equipment specifications, and the building itself before making these decisions. The basic physical characteristics of the building, including floor area, volume, height, and number of stories, are obviously important. Other important aspects of a building's physical layout include the manner in which the building is divided into zones, and the existence, size and layout of special-use spaces such as lobbies, atria, kitchens, cafeterias, conference rooms, and laboratories. Such special-use spaces often have dedicated mechanical ventilation systems and unique ventilation needs. The existence and design of ventilation and air distribution equipment is another important building feature that must be considered. These equipment issues include the number of fans, their role in ventilation and distribution (e.g. supply, return, exhaust, mixing), the amount of air they are intended to move, the manner in which they are controlled, and the particular zone within the building that they serve. In addition, the location of outdoor air intakes and exhaust vents, and their proximity to one another, are important factors. All of these features of a building must be studied and understood before the measurements are planned and conducted. This process of developing an understanding a building and its ventilation system requires a significant amount of effort but is absolutely essential in order to conduct a worthwhile investigation.

In addition to understanding the above features of a particular building, it is also important to understand and recognize the complex interactions between the ventilation equipment, building envelope, and interior configuration in determining a building's air exchange characteristics." It is impossible to consider these building systems in isolation because they interact so strongly. Measurements and modeling in mechanically ventilated office buildings have 
revealed the importance of these interactions (Persily and Grot 1985), specifically the influence of mechanical ventilation equipment operation and control on envelope infiltration rates.

\subsection{Instrumentation}

Tracer gas procedures have been used to measure air infiltration and ventilation characteristics of buildings for at least thirty years. These procedures require several pieces of equipment and other associated materials including tracer gases, a tracer gas concentration measuring device, air sampling and tracer gas injection equipment, and some means of controlling the measurement procedure and recording the data. Figure 1 is a schematic of a general tracer gas measurement system showing the major components of such a system.

A variety of tracer gases have been used in the past, and the desirable properties of tracer gases have been considered by Honma (1975) and by Hunt (1980). These include detectability, nonreactivity, nontoxicity and a relatively low concentration in ambient air. Several different detection devices can be used to measure tracer gas concentration, and the particular device that is used depends, of course, on the specific tracer gas. Several techniques used to measure tracer gas concentrations are listed in table 1 , along with some of the gases appropriate to each method. In selecting a tracer gas detector and designing one's measurement procedure, several characteristics of the detector need to be considered including the range of detectable concentrations, the device's analysis time, the required airflow rate through the device, and the need for expendables such as compressed gas or other chemicals.

Tracer gas measurements require an air sampling system to bring air from the various air sampling points within the building to the tracer gas detector. The complexity of this system can cover a wide range from that appropriate to a fully automated tracer gas measurement system to that used in a one-time, manual measurement. In its most complex form, an air sampling system consists of a series of appropriately sized pumps, air sample tubes running from the pumps to the air sample locations, and a manifold/valve set-up to enable selection from among the pump outlets for input to the tracer gas detector. In an automated system, this selection is accomplished by a control system. In a manual procedure, air sampling can involve containers, such as air sample bags or bottles, and a small pump to fill these containers. A series of these containers are filled during the test and hand-carried to the tracer gas detector for analysis. A tracer gas injection system is also required and, similarly, can cover a range of complexity. The injection system includes a supply of tracer gas and a means of injecting the gas at the desired locations within the building. An automated measurement system involves electronically controlled valves for turning the injection on and off and injection tubes running from the tracer gas injection valves to the injection sites. In a manual operation, one can fill syringes from a compressed gas cylinder, carry these syringes into the building, and empty them at the injection sites.

An automated tracer gas experiment must include some means of controlling the tracer gas injection and air sampling, as well as recording the measured tracer gas concentrations. Several micro-computer based data acquistion and control systems have been designed and used in tracer gas experiments (Condon et al 1980, Grot et al 1980, Hartmann and Mühlebach 1980, Kumar et al 1979) Because air exchange is so heavily influenced by weather conditions, it is 
important to measure and record environmental conditions during the measurements, including wind speed and direction and indoor and outdoor air temperatures. In an automated system, devices for measuring environmental conditions can be installed at the building site and their output recorded by the data acquisition and control system. In manual measurements, hand held devices can be used as well as reports from nearby weather stations. Other building conditions, such as fan operation and damper position, are also important to air exchange and need to be examined and recorded.

\section{FUNDAMENTALS OF TRACER GAS MEASUREMENTS}

There are three basic tracer gas techniques for measuring air exchange rates, decay, constant concentration, and constant injection. To understand these methods, one employs a mass balance of the tracer gas released within the building. Assuming that the tracer gas mixes thoroughly and instantaneously within the structure, this mass balance equation is

$$
V \dot{C}(t)=F(t)-q C(t)
$$

where $V$ is the building volume, $C(t)$ is the tracer gas concentration at time $t$, $\dot{C}$ is the time derivative of concentration, $q$ is the airflow rate out of the building, and $F$ is the tracer gas flow rate. The outdoor tracer gas concentration is assumed to equal zero.

The air exchange rate $I$ is given by

$$
I=q / V
$$

where $I$ is in air changes per hour $\left(h^{-1}\right)$. The solution to equation (I) is given by

$$
C(t)=C_{0} e^{-I t}+e^{-I t} \int_{0}^{t}\left(e^{I u} F(u) / v\right) d u
$$

where $C_{0}$ is the concentration at time $t=0$. For those cases in which $F$ is constant, the solution integrates further to

$$
C(t)=C_{0} e^{-I t}+(F / q)\left(1-e^{-I t}\right) \text {. }
$$

\subsection{Decay}

The simplest tracer gas technique is the tracer gas decay method, which has been discussed previously by Lagus (1980), and is the subject of a standardized measurement procedure (ASTM 1983). In the decay method, one injects a small amount of a tracer gas into the structure and allows the tracer to mix with the interior air. After the mixing period one monitors the rate of decay of the tracer gas concentration within the building. During the decay there is no source of tracer gas, hence $F(t)=0$ and the solution to $E q$ (1) is

$$
c(t)=c_{0} e^{-I t}
$$

Solving Eq (5) for I yields

$$
I=(1 / t) \ln \left[\left(C_{0} / C(t)\right]\right.
$$


where $C_{0}$ is the initial tracer gas concentration at $t=0$, when the decay begins.

To minimize errors in the determination of $I$ due to errors in the measurement of $\mathrm{C}(\mathrm{t})$ and $\mathrm{C}_{O}$, one can measure $\mathrm{C}$ periodically during the decay and fit the data to an equation of the form

$$
\ln C(t)=\ln C_{0}-I t
$$

The concentration measuring equipment can be located within the structure, or building air samples may be collected in suitable containers and analyzed offsite (Grot 1980; Harrje et al 1982).

As with all tracer gas techniques, there are advantages and disadvantages associated with the tracer gas decay method. The advantages include the fact that the equation used to determine the air exchange rate is an exact solution to the tracer gas mass balance equation. Also, because one takes logarithms of concentration, only relative concentrations are needed, which may simplify the calibration of one's concentration measuring device. Finally, one need not measure the tracer gas injection rate, although it must be controlled such that the tracer gas concentrations are within the range of one's concentration measuring device.

The most serious problem with the tracer gas decay technique is imperfect mixing of the tracer gas with the interior air, both at initial injection and during the decay. Equations (1) and (5) employ the assumption that the tracer gas concentration within the building is uniform and can be characterized by a single value. If the tracer gas is not well mixed, either within zones (e.g. floors or rooms) or between zones of a building, this assumption is not appropriate and the use of $\mathrm{Eq}(6)$ or (7) to determine I will lead to errors. It is extremely difficult to estimate the magnitude of the errors due to poor mixing, and there has only been very limited analysis of this problem (Hunt 1980). The only way to determine if there is or there is not good mixing is to monitor the tracer gas concentration at several locations within the building. It has been suggested (Dick 1949) that if one obtains different tracer gas decay rates in different rooms, due to poor mixing, one may obtain an estimate of the whole building air exchange rate using a volume-weighted average of the individual room decay rates.

\subsection{Constant Concentration}

In the constant concentration technique one injects appropriate quantities of tracer gas in order to maintain a constant concentration within the building. If the tracer gas concentration is truly constant, Eq (1) reduces to

$$
q(t)=F(t) / C
$$

This technique is less well developed than the tracer gas decay technique, but examples of its application do exist (Collet 1981; Bohac et al 1986).

An advantage of the constant concentration technique is that it can avoid some measurement problems that occur in the tracer gas decay procedure due to nonuniform mixing of the initial tracer gas injection. Because the tracer gas injection is continuous, there is no initial mixing period to be concerned with once the test is underway. There are, however, other serious mixing concerns as discussed below. Another advantage of the constant concentration technique is 
that one can separately control the tracer concentration in each zone of a building by separately injecting tracer into each zone, and thereby determine the amount of outdoor air flowing into each zone (Honma 1975; Sinden 1978). Tracer gas procedures appropriate to multi-chamber analysis are discussed further below.

This procedure has the disadvantages of requiring absolute concentration measurement and precise measurement of the tracer gas injection rates. Also, imperfect mixing of the tracer gas and the interior air causes a delay in the response of the tracer gas concentration to changes in the tracer gas injection rate. This delay in the concentration response, due to imperfect mixing, makes it essentially impossible to keep the concentration constant and therefore Eq (8) is actually an approximation. The errors induced by these mixing problems have not been well examined.

\subsection{Constant Injection}

The third technique for measuring air infiltration and ventilation is referred to as the constant injection or constant flow technique. In this procedure, one injects tracer at a constant rate and, setting $\mathrm{C}_{0}=0, \mathrm{Eq}(4)$ reduces to

$$
C(t)=(F / q)\left(1-e^{-I t}\right)
$$

After a sufficient period of time, the transient term reduces to zero, the concentration attains equilibrium, and one obtains the simple constant flow equation

$$
\mathrm{q}=\mathrm{F} / \mathrm{C} \text {. }
$$

This relation is valid only for cases in which the air exchange rate is constant, thus this technique is appropriate only for systems at or near equilibrium. This technique is particularly useful in areas with mechanical ventilation or in locations with high air exchange rates. The constant flow technique avoids the concentration control problems of the constant concentration procedure. The constant injection procedure requires the measurement of absolute concentrations and the tracer gas injection rate.

\subsection{Multi-Chamber Techniques}

The previous theory applies to structures that are modelled as a single zone, i.e., the tracer gas concentration within the building can be characterized by a single value. In many cases this assumption is inappropriate and a multichamber approach must be used (Sinden 1978). A variety of multi-chamber measurement techniques exist, involving the decay, constant concentration, and constant injection techniques, and the use of one or several tracer gases.

The equations describing the multi-chamber case are similar to Eq (1), except for the addition of airflow between chambers. A mass balance for each chamber yields,

$$
v_{i} \dot{C}_{i}=F_{i}-q_{i o} C_{i}+\sum_{j} q_{i j} C_{j}-\sum_{j} q_{j i} C_{i}
$$

where $V_{i}$ is the volume of chamber $i, C_{i}$ is the tracer gas concentration in that same chamber, $\dot{C}_{i}$ is its derivative with respect to time, $q_{i j}$ is the airflow rate 
from chamber $j$ to the chamber $i, q_{i o}$ is the airflow rate from chamber $i$ to outdoors, and $q_{i i}=0$. Note that as in the case of $\mathrm{Eq}$ (1), we are assuming that the outdoor tracer gas concentration is zero. For each tracer gas that is used, there will be one set of these equations, one equation for each zone. In designing and applying a multi-chamber experiment one must conceptually divide the building into separate zones, and it is not always obvious how to make these divisions.

\subsubsection{Decay}

The multi-chamber tracer gas decay method involves releasing the tracer gas as a pulse and then monitoring the concentration response in all of the chambers (Sinden 1978). The decay technique can be applied with a single tracer or several different tracer gases, and can be used to obtain the values of all the interzonal airflows $q_{i j}$ and $q_{i o}$. In the single tracer, multi-chamber decay approach, one injects tracer into a single zone and monitors the concentration response in all the zones. The measured concentrations are used in conjunction with Eq (11) to solve for the airflows. Depending on the characteristics of the airflow between the various zones, one such test may be sufficient to determine all of the airflows of interest. In general, however, several such tests will be required with the tracer being injected into a different zone each time. For this series of measurements to provide meaningful results, the airflows can not change significantly over the test period, generally an unreasonable expectation. To minimize the requirement for constant conditions, one can employ a multi-tracer decay technique in which a different tracer gas is injected into each zone and the concentration response of all the gases in all the zones is monitored. Both the single- and multi-tracer approaches make the assumption that each individual zone is prefectly mixed and that the test begins with a uniform tracer gas concentration in each zone. These assumptions are approximations at best and the errors associated with the actual conditions of imperfect mixing within zones and nonuniform initial conditions are not well known.

Several measurement systems employing the multi-tracer decay method have been developed, including those of Irwin et al (1984) and Prior et al (1983). Both systems employ gas chromatograph electron capture detectors, to measure refrigerants in the first system and perfluorocarbon tracers in the latter. I'Anson et al (1982) also employs a decay system involving refrigerant tracers. In figure 2, we show representative data from their paper in which two tracers are used to study the airflow between the upper and lower levels of a building. The refrigerant $\mathrm{C}_{2} \mathrm{Cl}_{2} \mathrm{~F}_{4}$ is injected downstairs and $\mathrm{CCl}_{2} \mathrm{~F}_{2}$ upstairs. The movement of tracer between the zones and the subsequent decay is evident in the data. Analysis of these data yields the airflow rates between the two zones and from each zone to the outdoors.

\subsubsection{Constant Concentration}

The constant concentration method can also be applied to study buildings in which a single zone approximation is inappropriate. As mentioned earlier one can separately control the tracer gas concentration in each zone of a building such that all zones are at the same target concentration $C^{\prime}$. This technique involves sampling the tracer gas concentration from, and injecting tracer into, each zone. The procedure can be used to determine the outdoor airflow rates into each zone $q_{i o}$, but not the interzonal airflow rates $q_{i j}$. Using Eq (11) and setting $\dot{C}_{i}(t)=0$ and $C_{i}(t)=C^{\prime}$, one obtains, 


$$
F_{i}=q_{i o} C^{\prime}
$$

From this equation one obtains values of $q_{i o}$ for each zone. The total air exchange rate of the building is determined by adding together all of the qio's. of course this procedure involves the same approximations as the single zone constant concentration procedure, i.e., that the concentration is maintained constant despite lags between the tracer gas injection and the concentration response due to imperfect mixing within a zone. Again, the errors associated with this mixing problem are not well known. As mentioned earlier, there have been several systems developed that employ the constant concentration procedure for multi-chamber studies (Collet et al 1981; Bohac et al 1986).

\subsubsection{Constant Injection}

The constant injection procedure can also be used to study multi-chamber air exchange by injecting a different tracer into each zone of a building at a constant rate and measuring the equilibrium concentrations of each tracer in each zone. By employing the appropriate form of Eq (11), one can solve for all of the interzonal airflow rates. This procedure is most appropriate for situations in which these airflows are fairly constant since one is assuming steady-state conditions in solving for the airflow rates. The multi-chamber, constant injection procedure is less well developed than some of the other multi-chamber techniques but some examples of its application exist.

Figure 3 shows an example of a constant injection measurement of ventilation and interzonal airflows in two adjacent, negative pressure laboratory rooms (Lagus 1984). The two laboratories are under negative pressure (as shown in the figure), and a different tracer gas is injected at a constant rate into each laboratory. The equilibrium tracer concentrations in each zone are shown in the figure. The measured airflow rates agree well with the ventilation rates measured by tracer gas decay. The presence of the refrigerant $\mathrm{CBrF}_{3}$ into the lower laboratory serves as evidence of undesired airflow between the laboratories.

A long-term averaging, constant injection technique has also been employed using perfluorocarbon tracers and passive samplers (Dietz and Cote 1982; Dietz et al 1984a). Long-term averaging, passive sampling techniques are discussed in more detail below. In these measurements, passive tracer sources are used to release a different tracer into each zone at a constant rate. The average concentration over the measurement period (which can range from hours to months) is determined in each zone with a passive sampler that collects tracer gas over the entire sampling period. From the injection rates and the average concentrations, one determines the airflows of interest. The determination of the airflow rates from Eq (11) involves an assumption that the concentration is at equilibrium, which can lead to measurement errors of unknown magnitude. Also, in solving these equations one uses average values of the terms $q_{i j} C_{i}$. Since one measures only the average of $C_{i}$, in order to solve for $q_{i j}$ one is making the assumption that the average of $q_{i j} C_{i}$ equals the average of $q_{i j}$ multiplied by the average of $C_{i}$. This is not a mathematicallly valid assumption except in very special cases, and therefore the calculations of $q_{i j}$ are subject to errors of unknown magnituide. Figure 4 is an example of measured airflows for a two zone case using this technique (Dietz et al 1984). 
In this section we discuss two applications of air exchange rate measurement. The first is tracer gas measurements of air exchange in large buildings, while the second application concerns low cost procedures for studying air exchange in large numbers of buildings.

\subsection{Tracer Gas Measurements in Large Buildings}

This section reviews techniques which employ a single tracer gas to measure infiltration and ventilation in large buildings, arbitrarily defined as structures with floor areas greater than about $5000 \mathrm{ft}^{2}\left(500 \mathrm{~m}^{2}\right)$. These buildings may have mechanical ventilation systems or they may be naturally ventilated. The types of large buildings that have been studied include office buildings, industrial buildings such as warehouses and airplane hangers, stores, shopping centers, and institutional facilities such as schools and hospitals. Most of the measurements in large buildings have employed the tracer gas decay method and this particular application is discussed below, along with other procedures applied to large buildings.

The basic approach of tracer gas decay measurements in large buildings is the same as that described earlier. The tracer gas is released into the building and allowed to $\mathrm{mix}$ with the interior air. The decay in the tracer gas concentration is monitored over time and the air exchange rate is determined from the decay rate. Several characteristics of large buildings influence the manner in which the decay method is applied in these structures. First, because of the large building volumes, the quantity of tracer gas required for a test and its cost become important. The expense depends on the cost per $\mathrm{m}^{3}$ of tracer gas, the building volume, and the magnitude of measurable tracer gas concentrations. Table 2 shows the range in the maximum building volume that can be measured for one dollar's worth of tracȩr gas (b̧ased on approximate 1986 prices). These volumes range from 4000 ft $\left(4003 \mathrm{~m}^{3}\right)$ for helium in the 300 parts per milition (ppm) range, to about $10^{6} \mathrm{ft}^{3}\left(10^{5} \mathrm{~m}^{3}\right)$ for carbon dioxide and nitrous oxide. The ability to measure $\mathrm{SF}_{6}, \mathrm{CBrF}_{3}$ and $\mathrm{PDCH}$ if the parts per trillion (ppt) range yields measurable volumes of $10^{8}$ to $10^{\text {to }} \mathrm{ft}^{3}$ (10 to $10^{9}$ $\mathrm{m}$ ) per dollar's worth of tracer gas. From this table it is apparent that tracer gases such as SF6, refrigerants, and perfluorocarbons analyzed at ppt, or even parts per billion, levels are most appropriate for large buildings. However, measurements have been performed in large buildings using infrared adsorption (Potter et al 1983; Zuercher and Feustel 1983) and flame ionization gas chromatography (Prior et al 1983).

The mixing of the tracer gas injection in these large building volumes is an important issue. Mixing by diffusion alone is a slow process; however, even in naturally ventilated buildings there are significant convective mixing mechanisms. In mechanically ventilated buildings the air distribution system can be used to mix the tracer gas, but mixing can still require fifteen minutes to one hour. In naturally ventilated buildings, tracer gas mixing is a more difficult problem. If the building interior is open with few internal partitions, then the gas will mix with the air, although it can take a long time. Fans can be used to mix the tracer, but they will alter the interior air movement, which may or may not affect the measurement results. The fans may be used to obtain an initially uniform concentration, and then be turned off during the decay. The only way to determine if good mixing has been achieved is to measure the tracer gas concentration at several locations within the building. 
The attainment of a uniform concentration is also assisted by injecting the gas at several locations.

In mechanically ventilated buildings fan operation and damper position are important issues. Most of these buildings have automatic control systems that turn fans on and off, modulate airflow rates and adjust exhaust, recirculation and supply damper positions. Thus, to conduct useful tracer gas measurements and interpret the results, one must be aware of the fan operating schedules and ventilation control strategies. One may make long term measurements in a building or conduct only a small number of tests. Long term studies are useful for examining the dependence of air leakage on weather and the performance of the ventilation control system. When making long term measurements, one's equipment, sensors and air sampling lines must be unobtrusive with regard to the building occupants and the automatic operation of the building equipment.

In this section we present an example of tracer gas decay measurements in mechanically ventilated office buildings. We also present other examples of air exchange measurements in large buildings. The example of measurements in a mechanically ventilated office building involves the use of automated equipment to conduct long term measurements (Grot et al 1980; Grot 1982). The tracer gas equipment is generally located in the building's mechanical equipment room where the main air handlers are located. Figure 5 is a schematic of such a building with the mechanical equipment room located in a penthouse. Most office buildings have separate air handlers, for spaces such as lobbies, which may be located some distance from the main mechanical equipment room. Such an air handler is shown in the figure. In order to obtain a uniform tracer gas concentration throughout the building, one must inject tracer into all the supply fans. This requires the installation of injection tubing that runs from the measurement equipment to each supply fan.

As seen in figure 5, the tracer gas concentration is measured at several locations within the building in order to verify that the tracer is indeed well mised. For example, one may sample in the building's main return duct, on individual floors and in the return ducts of any other air handlers. One must install air sample tubing connecting the measurement equipment to each of the sampling locations, and use pumps to bring the air to the measurement equipment. The individual floor sampling locations can be in the return air plenums immediately upstream of the return air shafts. In order for these sampling locations to give meaningful concentration measurements, the air handlers must be operating. In some buildings it may be possible to run the air sampling tubes into the occupied space in which case the air handlers need not be running during the tracer gas decay. Since building geometry and air.handler arrangements vary greatly among buildings, tracer injection and air sampling locations are different for each building.

In office buildings, there are two types of measurements that are of interest, referred to here as ventilation and infiltration. Ventilation rates refer to measurements made when the building HVAC system is operating normally under occupied conditions. In this case the various spill, recirculation and intake dampers open or close as the control system dictates in response to indoor and outdoor temperature and humidity, and time of day. Infiltration rates refer to the measurements obtained when the spill and intake dampers are closed (including any minimum outdoor air dampers). These test results give an indication of the airtightness of the building envelope. The operation of the fans during these measurements may be necessary for mixing, and their operation 
may affect the test results.

Short term measurements can also be made in such a building using injection and sampling by hand. The tracer is injected into the supply fans and air is collected in containers at locations throughout the building. The tracer gas concentrations in these containers are determined at some later time. This "manual" technique has a shorter set-up time than the automated procedure described above, but each infiltration measurement must be made by hand.

Long term automated infiltration and ventilation measurements have been made in several mechanically ventilated office buildings (Grot 1982; Grot and Persily 1983). In these tracer gas decay tests, hourly average infiltration and ventilation rates were measured for hundreds of hours in each building and the results were related to indoor-outdoor temperature difference and wind speed. The infiltration rates of the different buildings were found to exhibit varying degrees of weather dependence, and a range in the leakage of the building envelopes was observed. The ventilation rates reflected the strategies used to control the outdoor air intake rates and also revealed that uncontrolled envelope infiltration is generally an important portion of these building's total air exchange rates, even with significant amounts of outdoor air intake.

The tracer gas decay technique has been applied in an eleven-story office building, employing hand injection of the tracer gas and sampling of the interior air with polyethylene bottles (Harrje et al 1982). The tracer gas concentration in the bottles was later determined at a central location. The air was sampled on four different floors and in the main return duct of the air handler. Only a small number of measurements were made in the building, but the results demonstrated the utility of this "air sample container" technique in large buildings.

A small number of industrial buildings have also been studied with the tracer gas decay technique. These buildings are often characterized by large open volumes, such as warehouses, where tracer gas mixing can take a long time or require the use of fans. In a study of three large naturally ventilated single-zone structures in England, a fan was used to mix the tracer gas (Waters and Simons 1984). A uniform tracer gas concentration throughout the space was generally obtained within about twenty or thirty minutes after injection, although some spatial variation did remain. A series of tracer gas decay measurements in airplane hangers has also been conducted (Ashley and Lagus 1984).

There are other examples of the use of tracer gas in large buildings (Potter et al 1983; Zuercher and Feustel 1983). In one particular application, a constant injection scheme with gas bag sampling of the interior air was applied to a laboratory building (Freeman et al 1983). In these measurements, tracer gas was injected at a constant rate at twelve locations and the equilibrium tracer gas concentration was determined from air sample bags filled at twelve other locations. This "bag sample equilibrium" method was compared to measurements based on tracer gas decay and the agreement was good when mixing was thorough.

\subsection{Low Cost Measurement Procedures}

The tracer gas measurement techniques described above involve bringing sophisticated equipment for measuring tracer gas concentration to the building 
under investigation. Long-term measurements require one to leave this equipment in the building for extended periods of time. These studies provide immediate results and much detail, but they require expensive equipment and skilled professionals for installation. Several low-cost tracer gas measurement techniques have been developed that are useful for surveying the air leakage characteristics of large numbers of buildings. In addition, the field procedures can be handled by less well trained people. These techniques provide less information than long term studies, but for some applications the data collected are adequate. The low-cost procedures generally involve some device for on-site air sampling, with the tracer gas concentration of the air sample being subsequentially determined at a central location. Thus, a single tracer gas measuring device can be used to make air exchange measurements in many buildings. These techniques have generally been applied to homes, but they can also be used in large buildings.

\subsubsection{Decay Methods}

Low-cost tracer gas decay techniques are based on the same principles as other decay methods, and have been described previously (Grot 1980; Harxje et al 1982; Tamura and Evans 1983). They involve injection of the tracer gas into the building at an appropriate location or locations to facilitate achieving a uniform tracer gas concentration throughout the structure. After sufficient time is allowed for this mixing, air sample containers are filled at roughly equal time intervals. The containers are then sent to a central laboratory where the tracer gas concentration of each sample is measured. From the decay rate of the tracer gas concentration, one determines the average air exchange rate during the measurement period. The tracer gas injection and the air sampling requires careful attention by the field personnel, but the procedures themselves are not difficult. A variety of specific containers have been used including 30.5 in $^{3}(500 \mathrm{ml})$ flexible polyethylene bottles (Harrje et al 1982) 3 600 in $^{3}(10 \mathrm{~L})$ air sample bags (Grot 1980; Persily and Grot 1984), and 1.2 in $^{3}$ $(20 \mathrm{~mL})$ evacuated blood sample tubes (Tamura and Evans 1983). These low-cost decay methods have generally been applied to homes, but larger buildings have also been tested. A study of an eleven-story office building using the "bottle technique" has been mentioned earlier (Harrje et al 1982).

The low-cost of these techniques has enabled several surveys of the air leakage characteristics of large numbers of homes. In these surveys a small number of tracer gas decay tests are conducted in each home under a range of outdoor weather conditions. One study measured air infiltration rates in over two-hundred homes in low-income areas of the U.S. (Grot and Clark 1979). Another survey examined more than fifty pasive solar homes (Persily and Grot 1984). The low-cost of these measurement techniques enables the testing of large numbers of homes spread over a large geographical area with a single tracer gas concentration measuring device.

\subsubsection{Constant Injection}

Low-cost air infiltration measurement techniques based on the constant injection of a tracer gas into a building have also been developed. In these procedures, a tracer gas is injected at a constant rate and the interior air is continuously sampled to determine the average tracer gas concentration in the building over the sampling period. The average concentration and the injection rate are then related to the average infiltration rate over this same time period. In the low-cost versions of this technique, relatively simple devices are used for 
tracer gas injection and air sampling, while the tracer gas concentration of the air sample is determined with equipment at a central facility. All long-term average, constant injection measurement techniques have the problem that they actually determine the average of the inverse air exchange rate and not the average air exchange rate. The difference between the average of the inverse and the actual average depends on the distribution of air exchange rates during the measurement period. The magnitude of these differences are just beginning to be studied, but can be on the order of $20 \%$ for one-month averaging periods (Sherman and Wilson 1987). Longer averaging periods will generally lead to larger errors.

One version of the constant injection technique is the average infiltration monitor (AIM) developed at the Lawrence Berkeley Laboratory (Harrje et al 1981). This system employs suitcase-sized injectors and samplers to enable unattended measurement of long-term average infiltration rates. The injector contains a pump which slowly releases the tracer gas at a constant rate into the building. The sampler slowly fills a sample bag with a pump to obtain the average tracer gas concentration during the measurement period. The concentration in the sample bag is later determined at a central location. Another technique employs small passive injectors and samplers in a similar procedure. The Brookhaven National Laboratory Air Infiltration Monitoring System (BNL/AIMS) employs a perfluorocarbon tracer gas (PFT) which diffuses out at a known constant rate from a fluoroelastomer plug impregnated with the tracer (Dietz and Cote 1982; Dietz et al 1984 and 1986). The passive sampler is a small capillary adsorption tube which collects the PFT from the building interior during the test. The sampler is later analyzed to determine the average tracer gas concentration in the building, and hence the average (inverse) air exchange rate.

The application of these constant injection, long-term averaging techniques to large buildings requires that several tracer sources be used and that they are well-distributed throughout the building. Several samplers are also required. In mechanically ventilated office buildings the intermittent operation of fans, changing damper positions, and variations in outdoor air intake rates must be considered when using these techniques.

\section{OTHER TRACER GAS APPLICATIONS}

In this section tracer gas measurement procedures are discussed that characterize aspects of building air exchange and air movement other than building air exchange rates. These procedures include recently developed techniques to evaluate the performance of air distribution systems and to measure airflow rates associated with a ventilation system. In addition, procedures exist to pressure test the airtightness of large building envelopes and to evaluate building air movement in a qualitative manner.

\subsection{Air Distribution Evaluation}

Building ventilation systems are designed to satisfy minimum outdoor air intake levels (ASHRAE 1981) in order to provide a safe and comfortable environment for the building occupants. Even if the ventilation system is bringing in a sufficient amount of outdoor air, the air may not be well distributed within the interior space. In this case, not all of the air will be effective in maintaining acceptable indoor air quality within the space. The concept of ventilation effectiveness has been developed in order to quantify the air distribution system's ability to provide freshly conditioned air to the 
occupants and to remove internally generated pollutants. Many different definitions of ventilation effectiveness exist (Persily 1985) and can be divided into those that quantify the distribution of supply air and those that quantify pollutant removal effectiveness. A great deal of valuable ventilation effectiveness research has been conducted involving experiments in test rooms (Sandberg 1981 and 1983; Sandberg and Sjöberg 1983; Sandberg et al. 1982; Malmstrom and Ahlgren 1982; Skaret and Mathisen 1982 and 1985). These experiments have employed test rooms with reconfigurable intake and exhaust openings, and controllable supply air temperatures and ventilation rates, to study the dependence of ventilation effectiveness on these variables. The procedures employed in these laboratory measurements can also be used to measure ventilation effectiveness in actual buildings.

Several definitions and theoretical frameworks have been used to discuss ventilation effectiveness, but there are essentially two basic approaches. The first type of ventilation effectiveness measures can be referred to as "concentration efficiencies" and are based on relations between gas concentrations in the supply air, the exhaust air, and the air at various locations in the space. Efficiencies based on age distributions and residence times, using approaches of chemical reactor engineering, constitute the second approach to ventilation effectiveness. For a detailed review of the various definitions of ventilation effectiveness and the associated measurement techniques see Persily (1985), as well as the original articles on the material (Malmstrom and Ahlgren 1982; Sandberg 1981 and 1983; Sandberg and Sjoberg 1983; Skaret and Mathisen 1982).

The techniques for quantifying air distribution effectiveness in actual buildings are still being studied. No standard procedures exist yet for typical North American buildings, but the procedures based on age distribution theory appear to have potential for being useful and are therefore discussed below with reference to mechanically ventilated office buildings. Ventilation

effectiveness definitions based on age distributions involve average and local ages of the interior air, and tracer gases can be used to determine these ages. The measured values of these ages are compared to each other or to their values for idealized reference cases (i.e., perfect mixing or pure plug flow through the space) to determine various ventilation effectivenesses.

In age distribution theory applied to ventilation effectiveness, one considers three populations of air parcels for a given ventilated space of volume $V$ and volumetric air exchange rate $q$ : the air at some specific location within the space, all of the air contained in the space, and the air leaving the space. One defines the average age of the air at a specific location by considering all the air molecules at that location and determining the average amount of time that has elapsed since these air molecules entered the space or building. The average age of the air at a point $i$ is denoted as $t_{i}$. One defines the average age of all the air in a given space, denoted by [t], as the average value of $t_{i}$ for all locations in the space under consideration. One may also consider the age of the air leaving the room, denoted by $t_{n}$, which is equal to the inverse of the air exchange rate, i.e. (V/q), regardless of the airflow patterns within the space (Sandberg and Sjoberg 1983).

It is revealing to compare the values of the local air age $t_{i}$, the average age of the air in the space [t] and the age of the air leaving the space $t_{n}$, for three reference cases. First, if the air within the space under consideration is perfectly mixed, then all the local ages have the same value throughout the 
space, equal to $[t]=t_{n}$. In addition, contaminant concentrations are identical throughout the space. For the second case, pure piston flow from the supply to the exhaust, the value of $t_{i}$ depends on the particular location within the space, with its value increasing from 0 to $t_{n}$ as $i$ moves from the supply to the exhaust. The average age of the air in the space [ $t$ ] is equal to $t_{n} / 2$. For pure piston flow, the effectiveness of pollutant removal and outdoor air distribution are maximized, but thermal comfort may be compromised due to excessive air velocitites or low air temperatures near the supply vents. In addition, occupants located immediately downstream of a pollutant source will be subjected to higher contaminant concentrations than in the case of perfect mixing. The third case is often referred to as "short circuiting," in which a portion of the supply air flows directly into the exhaust vent without mixing with the rest of the space air. In this situation, the value of $t_{i}$ again depends on the location of $i$. In stagnant zones that are bypassed by the supply air, $t_{i}$ is greater than [ $\left.t\right]$ and $t_{n}$. In the regions through which the shortcircuiting flow passes, $t_{i}$ is less than [t] and $t_{n}$. The average age of the air within the space [t] is greater than $t_{n}$. Such short-circuiting flow has serious negative implications for indoor air quality because the ventilation air is only partially effective in providing outdoor air to the occupants and removing internally generated pollutants. Depending on the degree of short-circuiting, the concentrations of internally generated contaminants in the stagnant zones can be much higher than for the cases of perfect mixing and piston flow.

Comparisons of $t_{i},[t]$, and $t_{n}$ serve as the basis for definitions of ventilation effectiveness. Several such definitions exist, but only two are presented here, the mean air exchange effectiveness $\mathrm{n}$ and the local air exchange effectiveness $e_{i}$. The mean air exchange effectiveness quantifies the overall aix distribution pattern for a space and is given by

$$
n=t_{n} /[t] \text {. }
$$

$\mathrm{n}$ achieves its maximum value under conditions of pure piston flow for which $\mathrm{n}=2$. If there is perfect mixing, then $n=1$, and if there is short circuiting of the supply to the exhaust, then $\mathrm{n}$ is less than 1 . The local air exchange effectiveness quantifies local conditions and is given by

$$
e_{i}=[t] / t_{i}
$$

$e_{i}$ can range from zero to infinity, and in the case of perfect mixing equals 1.0 throughout the space. For pure piston flow, the value of $e_{i}$ depends on the specific location within the space being considered. Near the supply, $t_{i}$ is close to zero and $e_{i}$ is much greater than one. In the middle of the room, $t_{i}=$ $t_{n} / 2$ and $e_{i}=1.0$. And as one approaches the exhaust, $t_{i}$ approaches $t_{n}$, and $e_{i}$ approaches 0.5 . In the case of short circuiting, for a location within one of the so-called stagnant zones, $t_{i}>[t]$ and $e_{i}<1$, a generally undesirable situation.

One may employ a tracer gas to measure these ages using several techniques that differ primarily in the tracer gas injection location and duration (Sandberg 1983). One of the measuring techniques involves injecting tracer at a constant rate into the supply airstream and monitoring the build-up in tracer gas concentration in the exhaust vent and at various locations within the space until equilibrium is attained. In another technique, one begins with a uniform tracer gas concentration throughout the space and monitors the decay in concentration in the exhaust and within the space. The measuring procedures 
have been used successfully in one- and two-room laboratory test facilities [Sandberg 1983; Sandberg and Sjöberg 1983; Sandberg et al. 1982; Skåret and Mathisen 1982, 1985], but the application of these procedures in actual buildings is much more complex. There are several features of real buildings, particularly large, mechanically ventilated office buildings, that complicate the application of age distribution measuring techniques (Persily 1987). The theory of age distributions consider the ventilated space as a single zone with a small number of well-defined supply and exhaust (return) vents. The space is also assumed to have no airflow into or out of the space except through the mechanical ventilation system, a concern that was discussed earlier. In reality, the ventilation of an office space is much more complicated that this theory assumes. Office spaces communicate freely with adjoining spaces and with the outdoors through leaks in the building envelope. There are generally many supply vents serving a space and the number of return air vents is extremely variable among rooms, with some rooms having no return vents at all. This situation presents several problems for applying age distribution measuring techniques. These and other factors complicate the application of age distribution measuring techniques in modern North American office buildings and the interpretation of the test results, but research is currently in progress to develop measurement protocols that are appropriate to these field situations.

\subsection{Ventilation System Airflow Rates}

As mentioned earlier, tracer gas measurements of air exchange rates in mechanically ventilated buildings determine the sum of the uncontrolled envelope leakage and the intentional outdoor air intake through the air handling system. Tracer gas procedures exist to measure these quantities simulataneously, as well as other airflow rates of interest in understanding the air exchange characteristics of mechanically ventilated buildings (Persily and Norford 1987). These quantities can be measured using two different techniques, a steady-state, constant injection tracer gas procedure and a procedure combining tracer gas decay and airflow measuring stations. Both techniques are described below.

The constant injection procedure is illustrated in the schematic in Figure 6. In this schematic $Q_{O A}$ is the rate of intentional outdoor air intake through the air handling system, $Q_{R C}$ is the recirculation airflow rate, and $Q_{S U}$ is their sum, the supply airflow rate. QIN is the rate of uncontrolled air leakage into the building through the building envelope, and QEX is the sum of the uncontrolled air leakage out through the building envelope and the airflow out of intentional openings such as bathroom exhausts. QRE is the return airflow rate and $Q_{S P}$ is the airflow rate through the spill dampers.

In the constant injection measurement procedure, one injects tracer gas at a constant rate $F$ into the supply airstream as indicated in Figure 6 . In this procedure, the value of the outdoor air tracer gas concentration must be constant, and for many tracer gases it will equal zero. The equations below are developed under the assumption that the outdoor concentration is zero, but an alternative set of equations can be easily developed for an outdoor concentration that is nonzero but constant. During the test, one measures the return air tracer gas concentration $C_{R}$, the supply air concentration $C_{S}$, and the mixed-air concentration $C_{M}$. $C_{M}$ must be measured some distance downstream of the location where the recirculation air meets the new outdoor air in order to provide the two airstreams an opportunity to mix. Similarly, $\mathrm{C}_{S}$ must be measured downstream of the tracer gas injection location, after the tracer mixes with the supply airstream. The tracer gas mixing can be enhanced by releasing 
the tracer at several locations across a supply duct cross-section. In employing this measurement procedure, one must wait for the tracer gas concentrations to reach steady-state conditions, which can take several hours depending on the net ventilation rate of the building, the amount of recirculation of the return air, and the extent of air mixing within the building.

Based on the tracer gas injection rate $F$ (in units of volumetric flow rate), and the equilibrium values of the supply, return and mixed-air tracer concentrations, one can determine the values of $Q_{O A}, Q_{I N}, Q_{R C}$ and $Q_{S U}$ as follows. The value of $Q_{S U}$ is determined from the increase in concentration across the tracer gas injection in the supply airstream location according to

$$
C_{S}-C_{M}=F / Q_{S U}
$$

Based on a mass balance of tracer gas at the point where the recirculation air mixes with the outdoor air, one obtains $\mathrm{Q}_{\mathrm{RC}}$ from the following equation

$$
Q_{R C} C_{R}+Q_{O A} C_{\text {out }}=Q_{S U} C_{M}
$$

Assuming the outdoor concentration of tracer gas $C_{\text {out }}$ is zero, Eq 16 can be rearranged to yield

$$
Q_{R C}=\left(C_{M} / C_{R}\right) Q_{S U}
$$

The outdoor air intake rate $Q_{O A}$ can be determined from the values of $Q_{S U}$ and $Q_{R C}$ and a mass balance of airflows where the outdoor and recirculation air mix, i.e.,

$$
Q_{O A}=Q_{S U}-Q_{R C}
$$

The rate of envelope infiltration QIN can be determined by tracer gas and airflow mass balances on the total building system

$$
\left(Q_{O A}+Q_{\text {IN }}\right) C_{\text {out }}+F=\left(Q_{E X}+Q_{S P}\right) C_{R}
$$

and

$$
Q_{E X}+Q_{S P}=Q_{O A}+Q_{I N}
$$

Again assuming $C_{\text {out }}$ equals zero, Eqs 19 and 20 can be combined to yield

$$
Q_{O A}+Q_{I N}=Q_{A E}=F / C_{R} \text {. }
$$

$Q_{A E}$ is the total air exchange rate of the building. Based on the value of $Q_{O A}$ obtained from Eq 18, Eq 21 can be used to determine QIN. Each determination of these airflows requires several hours to reach equilibrium, and the damper positions and fan airflow rates must be essentially constant during the measurement. When these conditions are altered, one must again wait another few hours to determine the quantities of interest at the new airflow conditions.

Alternatively, one may use a tracer gas decay/airflow rate measuring station procedure to determine these same quantities. In this procedure one conducts a tracer gas decay test to determine the total air exchange rate of the building, while simultaneously measuring the supply airflow rate with an appropriate airflow rate measuring device. The tracer gas measurement involves 
injecting a small amount of tracer into the building, generally into the building supply airstream, waiting for the tracer to mix thoroughly with the interior air, and monitoring the decay rate of the tracer gas concentration over time. The decay rate of the tracer concentration is used to determine the building air exchange rate $Q_{A E}=Q_{O A}+Q_{I N}$. During the tracer gas decay measurement, an airflow rate measuring station is used to determine the supply airflow rate. From these measurements, one can determine all of the quantities of interest.

During the tracer gas decay, one determines the building air exchange rate by monitoring the return air tracer concentration $C_{R}$, which decreases according to the following equation:

$$
C_{R}=C_{R o} e^{-I t}
$$

where $t$ is time, $C_{R o}$ is the return air tracer gas concentration at $t=0$, and $I_{r}$ is the slope of $\operatorname{lnC}_{R}$ versus time. $I_{r}$ is equal to $Q_{A E}$ divided by the building volume $V$. In this measurement procedure, one also monitors the supply air tracer gas concentration $\mathrm{C}_{S}$, which is given by

$$
C_{S}=C_{S o} e^{-I t}
$$

where $C_{S o}$ is the supply air concentration at $t=0$ and $I_{S}$ is the slope of $\operatorname{lnC}_{S}$ versus time. Theoretically $I_{S}$ equals $I_{r i}$ however, measurement errors can lead to differences between these two quantities.

Given constant aix intake and recirculation rates, the ratio of $\mathrm{C}_{R}$ and $\mathrm{C}_{S}$ will be constant and can be used to determine the percent of outdoor air intake, i.e., $Q_{O A} / Q_{S U}$. This determination employs mass balances of tracer gas and airflow at the point where the recirculation and outdoor air intake airflows mix. These mass balances take the forms of Eqs 17 and 18 . In this procedure $C_{M}$ $=C_{S}$, and these two equations can be combined to yield

$$
Q_{O A} / Q_{S U}=1-\left(C_{S} / C_{R}\right)
$$

At this point one employs the airflow rate measuring station to determine QSU. Such a station can consist of multi-point arrays of pitot tubes, thermistors or hot wire anemometers, or other airflow measuring devices. other airflow rates, such as the return and spill airflows, can also be measured if this additional information is desired. Whatever airflow measuring devices are used, they must be employed properly, i.e., factors such as lengths of upstream ductwork must be considered. In some ventilation systems it may be very difficult to employ an airflow measuring device in a manner yielding reliable measurements.

From the measured values of $Q_{S U}$ and Eq 24, one determines $Q_{O A}$. From the value of $Q_{A E}$ determined from the tracer gas decay, one determines QIN $\left(=Q_{A E}\right.$ $\left.Q_{O A}\right)$. As in the case of the constant injection tracer gas procedure, the damper positions and fan airflow rates must be essentially constant during the measurement.

Both the constant injection procedure and the tracer gas decay/airflow rate measuring station procedure are somewhat limited when there are multiple air handlers serving building zones that exchange air with one another. Only if there is no mixing between zones can the above analysis be used in each zone to 
separately determine the envelope infiltration rate into that zone. In the more general case of some mixing between zones, using the tracer gas decay/airflow rate measuring procedure, one can only determine the outdoor air intake rate into each zone and the tracer gas decay rate for each zone. If there is sufficient mixing between zones, then the tracer gas decay rate will be identical for all the zones and equal to the total building air exchange rate. Even if the mixing is not perfect, the volume-weighted average tracer gas decay rate for all the zones can be used as an approximation of the total building air exchange rate. Based on the measured outdoor air intake rates for all the zones and the total building air exchange rate, one can determine the total building envelope infiltration rate.

\subsection{Pressurization Testing of Large Building}

The constant injection technique has been used to measure airflow rates in the evaluation of the airtightness of large building envelopes using pressurization testing. In pressurization testing, a fan induces a large pressure difference across the building envelope and the airflow rate required to induce this pressure difference is measured. The airflow rate associated with a specific indoor-outdoor pressure difference is a measure of the airtightness of the building envelope. The airflow can be induced with a large fan which is brought to the building for the test or with the building's air handling equipment. Various means exist for measuring the airflow rate through the fan, but a constant injection tracer gas method has been used in some cases. This is a simple technique which does not require the duct lengths and flow straighteners associated with other flow measurement techniques.

To measure the airflow rate with the constant injection tracer gas method, tracer gas is injected into the airstream at a constant and known rate. The tracer injection is generated using a compressed gas cylinder with a flowmeter such as a critical orifice, a float-type rotameter or an electronic flow controller. The tracer concentration is then measured as far downstream as possible from the injection point. Under conditions of perfect mixing of the tracer gas and the airflow, the airflow rate can be determined from the tracer injection rate and the measured concentration (see Eq (10)).

Several large industrial buildings have been pressure tested using a fan that was brought to the buildings and employing the flow measurement technique described above (Lundin 1984). Figure 7 shows a schematic of the flow measurement equipment used in these tests. The same flow measurement procedure was applied to seven modern office buildings in which the building supply fans were used to pressurize the structure (Persily and Grot 1984a). Figure 8 shows a schematic of the test arrangement including the fan operating conditions, damper positions, tracer gas injection location and tracer gas concentration measurement point.

\subsection{Qualtitative Evaluation Techniques}

It should be noted that one does not require the full solutions to Eq (1) to obtain useful information regarding a building's air exchange characteristics with tracer gases. A significant amount of qualitative information can be obtained using tracer gases in buildings. For example, the existence of the movement of air from one location to another can be verified by releasing tracer gas at the first location and measuring the concentration at the second. This simple procedure can be used to examine the occurence of reentrainment of 
exhaust air into an outdoor air intake, movement of air from one location within a building to another, or to verify the isolation of a special-use space from the rest of a building. All such applications require extreme care regarding the tracer gas injection to insure that the tracer is released only at the intended location, such that any tracer detected elsewhere is due only to airflow and not to unintentional tracer release. 
ASHRAE, "Ventilation for Acceptable Indoor Air Quality," Standard 62, American Society for Heating, Refrigerating, and Air-Conditioning Engineers, Inc., 1981.

ASTM, "Standard Practice for Measuring Air Leakage Rates by the Tracer Dilution Method", E 741-83, American Society for Testing and Materials, 1983.

Alexander, D.K., Etheridge, D.W., Gale, R. "Experimental Techniques for Ventilation Research," in Air Infiltration Instrumentation and Measuring Techniques, proceedings of the First Air Infiltration Centre Conference, Berkshire, UK, 1980.

Ashley, J.L., Lagus, P.L., "Air Infiltration Measurements in Large Military Aircraft Hangers," in Measured Air Leakage of Buildings, ASTM STP 904, H.R. Trechsel and P.L. Lagus, Eds., American Society for Testing and Materials, Philadelphia, 1986.

Bohac, D., Harrje, D., Norford, L.K., "Constant Concentration Infiltration Measurement Technique: An Analysis of its Accuracy and Field Measurements," Proceedings of the ASHRAE/DOE/BTECC Conference Thermal Performance of the Exterior Envelopes of Buildings III, ASHRAE SP 49, 1986.

Collet, P.F., "Continuous Measurements of Air Infiltration in Occupied Dwellings," in Building Design for Minimum Air Infiltration proceedings of the Second Air Infiltration Centre Conference, Stockholm, 1981.

Condon, P.E., Grimsrud, D.T., Sherman, M.H., Kammerud, R.C., "An Automated Controlled-Flow Air Infiltration Measurement System," in Building Air Change Rate and Infiltration Measurement eds., Hunt, C.M., King, J.C., and Trechsel, H.R., ASTM STP 719, American Society for Testing and Materials, 1980 .

Dick, J.B., "Experimental Studies in Natural Ventilation of Houses," Journal of the Institution of Heating and Ventilating Engineers, December 1949 .

Dietz, R.N., Cote, E.A., "Air Infiltration Measurements in a Home Using a Convenient Perfluorocarbon Tracer Technique," Environment International, Vol.8, 1982 .

Dietz, R.N., Goodrich, R.W., Cote, E.A., Wieser, R.F., "Application of Perfluorocarbon Tracers to Multizone Air Flow Measurements in Mechanically and Naturally Ventilated Buildings," Brookhaven National Laboratory Report 35249 , 1984 .

Dietz, R.N., Goodrich, R.W., Cote, E.A., Wieser, R.F., "Detailed Description and Performance of a Passive Perfluorocarbon Tracer System for Building Ventilation and Air Exchange Measurement," in Measured Air Leakage of Buildings, ASTM STP 904, H.R. Trechsel and P.L. Lagus, Eds., American Society for Testing and Materials, Philadelphia, 1986.

Freeman, J., Gale, R., Lilly, J.P., "Ventilation Measurements in Large Buildings," in Air Infiltration Reduction in Existing Buildings proceedings of the Fourth Air Infiltration Centre Conference, Elm, Switzerland, 1983. 
Grot, R.A., Clark, R.E., "Air Leakage Characteristics and Weatherization Techniques for Low Income Housing," in Proceedings of the DOE/ASHRAE Conference on the Thermal Performance of the Exterior Envelopes of Buildings, Orlando, FL, December 1979.

Grot, R.A., "A Low-Cost Method for Measuring Air Infiltration Rates in a Large Sample of Dwellings," in Building Air Change Rate and Infiltration Measurement eds., Hunt, C.M., King, J.C., and Trechsel, H.R., ASTM STP 719, American Society for Testing and Materials, 1980.

Grot, R.A., Hunt, C.M., Harrje, D.T., "Automated Air Infiltration Measurements in Large Buildings," in Air Infiltration Instrumentation and Measuring Techniques proceedings of the First Air Infiltration Centre Conference, Berkshire, UK, 1980.

Grot, R.A., "The Air Infiltration and Ventilation Rates in Two Large Commercial Buildings:" DOE/ASHRAE Conference on Thermal Performance of the Exterior Envelopes of Buildings II, Las Vegas, Nevada, December 1982.

Grot, $R_{0} A_{0}$, Persily, A.K., "Air Infiltration and Air Tightness Tests in Eight U.S. Office Buildings, in Air Infiltration Reduction in Existing Buildings proceedings of the Fourth Air Infiltration Centre Conference, Elm, Switzerland, September 1983.

Harrje, D.T., Gadsby, K., Iinteris, G., "Sampling for Air Exchange: Rates in a Variety of Buildings," ASHRAE Transactions, Vol.88(I), 1982.

Harrje, D.T., Grot, R。A., Grimsrud, D.T., "Air Infiltration Site Measurement Techniques," in Building Design for Minimum Air Infiltration proceedings of the Second Air Infiltration Centre Conference, Stockholm, Sweden, 1981.

Hartmann, P., Mühlebach, H., "Automatic Measurements of Air Change Rates (Decay Method) in a Small Residential Building without Any Forced-Air-Heating System," in Air Infiltration Instrumentation and Measuring Techniques, proceedings of the First Air Infiltration Centre Conference, Berkshire, UK, 1980 .

Hitchin, E.R. Wilson, C.B., "A Review of Experimental Techniques for the Investigation of Natural Ventilation in Buildings," Building Science, Vol.2, 1967.

Honma, H., "Ventilation of dwellings and its disturbances," FAIBO Grafiska, Stockholm, 1975 .

Hunt, C.M., "Air Infiltration: A Review of Some Existing Measurement Techniques and Data," in Hunt, C.M., King, J.C., and Treschsel, H.R., eds., Building Air Change Rate and Infiltration Measurements, STP 719, American Society for Testing and Materials, Philadelphia, 1980.

I'Anson, S.I., Irwin, C., Howarth, A.T., "Air Flow Measurement Using Three Tracer Gases," Building and Environment, Vol. 17, 1982.

Irwin, C., Edwards, R.E., Howarth, A.T., "An Improved Multiple Tracer Gas Technique for the Calculation of Air Movement in Buildings," Air Infiltration Review, Vol.5, No.2, February 1984. 
Kumar, R., Ireson, A.D., Orr, H.W., "An Automated Air Infiltration Measuring System Using $\mathrm{SF}_{6}$ Tracer Gas in Constant Concentration and Decay Methods," ASHRAE Transactions, Vol.85, Part 2, 1979.

Lagus, P.L. "Air Leakage Measurements by the Tracer Gas Dilution Method Review," in Building Air Change Rate and Infiltration Measurement eds., Hunt, C.M., King, J.C., and Trechsel, H.R., STP 719, American Society for Testing and Materials, Philadelphia, 1980.

Lagus, P.L., Unpublished Study, 1984.

Lundin, L., "Fan Pressurization of Industrial Buildings - Description of Equipment and Measuring Results," in Measured Air Leakage of Buildings, ASTM STP 904, H.R. Trechsel and P.L. Lagus, Eds., American Society for Testing and Materials, Philadelphia, 1986.

Malmström, T., Ahlgren, A., "Efficient Ventilation in Office Rooms," Environment International, Vol.8, 1982 .

Persily, A.K., "Ventilation Effectiveness in Mechanically Ventilated office Buildings," NBSIR 85-3208, National Bureau of Standards, 1985.

Persily, A.K., "Ventilation Effectiveness Measurements in an Office Building," in Proceedings of ASHRAE IAQ86, Atlanta, GA, 1986.

Persily, A.K., Grot, R.A., "Air Infiltration and Building Tightness Measurements in Passive Solar Residences," ASME Journal of Solar Energy Engineering, Vol.8 No.2, May 1984.

Persily, A.K., Grot, R.A., "Pressurization Testing of Federal Buildings," in Measured Air Leakage of Buildings, ASTM STP 904, H.R. Trechsel and P.L. Lagus, Eds., American Society for Testing and Materials, Philadelphia, 1986 .

Persily, A.K., Grot, R.A., "The Airtightness of Office Building Envelopes," in Proceedings of the ASHRAE/DOE/BTECC Conference on the Thermal Performance of the Exterior Envelopes of Buildings III, Clearwater Beach, FL, 1985.

Persily, A.K., Norford, L.N., "Simultaneous Measurements of Infiltration and Intake in an Office Building," ASHRAE Transactions, Vol.93, Part 2, 1987.

Potter, N., Dewsbury, J., Jones, T., "The Measurement of Air Infiltration Rates in Large Enclosures and Buildings," in Air Infiltration Reduction in Existing Buildings proceedings of the Fourth Air Infiltration Centre Conference, Elm, Switzerland, September 1983.

Prior, J., Littler, J., Adlard, M., "Development of Multi-tracer Gas Technique for Observing Air Movement in Buildings," Air Infiltration Review, Vol.4, No.3, May, 1983.

Sandberg, M., "What is Ventilation Efficiency?" Buildings and Environment, Vol.16, No.2, 1981.

Sandberg, M., "Ventilation Efficiency as a Guide to Design," ASHRAE Transactions, Vol.89, Part 2, 1983. 
Sandberg, M., Sjöberg, M., "The Use of Moments for Assessing Air Quality in Ventilated Rooms," Buildings and Environment, Vol.18, No.4, 1983.

Sandberg, M., Blomqvist, C., Sjoberg, M., "Warm Air Systems. Part 2. Tracer Gas Measurements and Ventilation Efficiencies," Bulletin M82:23, The National Swedish Institute for Building Research, 1982.

Skåret, E., Mathisen, H.M., "Ventilation Efficiency - A Guide to Efficient Ventilation," ASHRAE Transactions, Vol.89, Part 2, 1983.

Skåret, E., Mathisen, H.M., "Test Procedures for Ventilation Effectiveness Field Measurements," in Proceedings of the International Symposium on Recent Advances in the Control and Operation of Building HVAC Systems, Trondheim, Norway, 1985.

Sherman, M.H., Grimsrud, D.T., Condon, P.E., Smith, B.V., "Air Infiltration Measurement Techniques," in Air Infiltration Instrumentation and Measuring Techniques proceedings of the First Air Infiltration Centre Conference, Berkshire, UK, 1980.

Sherman, M.H., Wilson, D.J., "Relating Actual and Effective Ventilation in Determining Indoor Air Quality," Buildings and Environment, Vol.21, No.3/4, 1986.

Sinden, F.W., "Multi-Chamber Theory of Air Infiltration," Building and Environment, Vol. 13, 1978.

Tamura, G.T., Evans, R.G., "Evaluation of Evacuated Glass Tubes for Sampling SF 6/Air Mixture for Air Exchange Measurements," ASHRAE Journal, October 1983.

Waters, J.R., Simons, M.W., "The Measurement of Air Infiltration in Large Single Cell Industrial Buildings," in Measured Air Leakage of Buildings, ASTM STP 904, H.R. Trechsel and P.L. Lagus, Eds., American Society for Testing and Materials, Philadelphia, 1986.

Zuercher, $\mathrm{CH}$, Feustel, $\mathrm{H}$, "Air Infiltration in High-Rise Buildings," in Air Infiltration Reduction in Existing Buildings proceedings of the Fourth $\bar{A}$ ir. Infiltration Centre Conference, Elm, Switzerland, 1983. 
Thermal Conductivity Detector

Electron Capture Gas Chromatograph

Flame Ionization Gas Chromatograph

Infrared Absorption
Hydrogen

Helium

Carbon Dioxide

Sulfur Hexafluoride

Refrigerants

Perfluorocarbons

Ethane

Carbon Monoxide

Carbon Dioxide

Sulfur Hexafluoride

Nitrous Oxide

Ethane

Methane

TABLE 2

RELATIVE TRACER GAS COSTS TAKING DETECTABILITY INTO ACCOUNT

\begin{tabular}{|c|c|c|c|c|c|}
\hline \multirow[t]{2}{*}{ Gas } & \multirow{2}{*}{$\begin{array}{c}\text { Detectable } \\
\text { Concentration } \\
(\mathrm{ppm})\end{array}$} & \multicolumn{2}{|c|}{$\begin{array}{l}\text { Gas Volume } \\
\text { Per Dollar }\end{array}$} & \multicolumn{2}{|c|}{$\begin{array}{l}\text { Maximum Measureable } \\
\text { Volume Per Dollar }\end{array}$} \\
\hline & & $\mathrm{ft}^{3}$ & $\left(m^{3}\right)$ & $\mathrm{ft} \mathrm{t}^{3}$ & $\left(m^{3}\right)$ \\
\hline $\mathrm{He}$ & 300 & 1.4 & $(0.13)$ & $4 \times 10^{3}$ & $\left(4 \times 10^{2}\right)$ \\
\hline $\mathrm{CO}_{2}$ & 1 & 7.0 & $(0.65)$ & $6 \times 10^{4}$ & $\left(6 \times 10^{5}\right)$ \\
\hline $\mathrm{N}_{2} \mathrm{O}$ & 1 & 2.4 & $(0.22)$ & $2 \times 10^{6}$ & $\left(2 \times 10^{5}\right)$ \\
\hline $\mathrm{SF}_{6}$ & $5 \times 10^{-6}$ & 0.13 & $\left(1.2 \times 10^{-2}\right)$ & $2 \times 10^{10}$ & $\left(2 \times 10^{9}\right)$ \\
\hline$"$ & $5 \times 10^{-3}$ & $\because$ & $"$ & $2 \times 10^{7}$ & $\left(2 \times 10^{6}\right)$ \\
\hline $\mathrm{CBrF}_{3}{ }^{*}$ & $5 \times 10^{-5}$ & $3.7 \times 10^{-2}$ & $\left(3.4 \times 10^{-3}\right)$ & $7 \times 10^{8}$ & $\left(7 \times 10^{7}\right)$ \\
\hline $\mathrm{PDCH}$ * & $5 \times 10^{-6}$ & $3.0 \times 10^{-3}$ & $\left(2.8 \times 10^{-4}\right)$ & $6 \times 10^{8}$ & $\left(6 \times 10^{7}\right)$ \\
\hline
\end{tabular}

* bromotrifluoromethane

** perfluorodimethylcyclohexane 



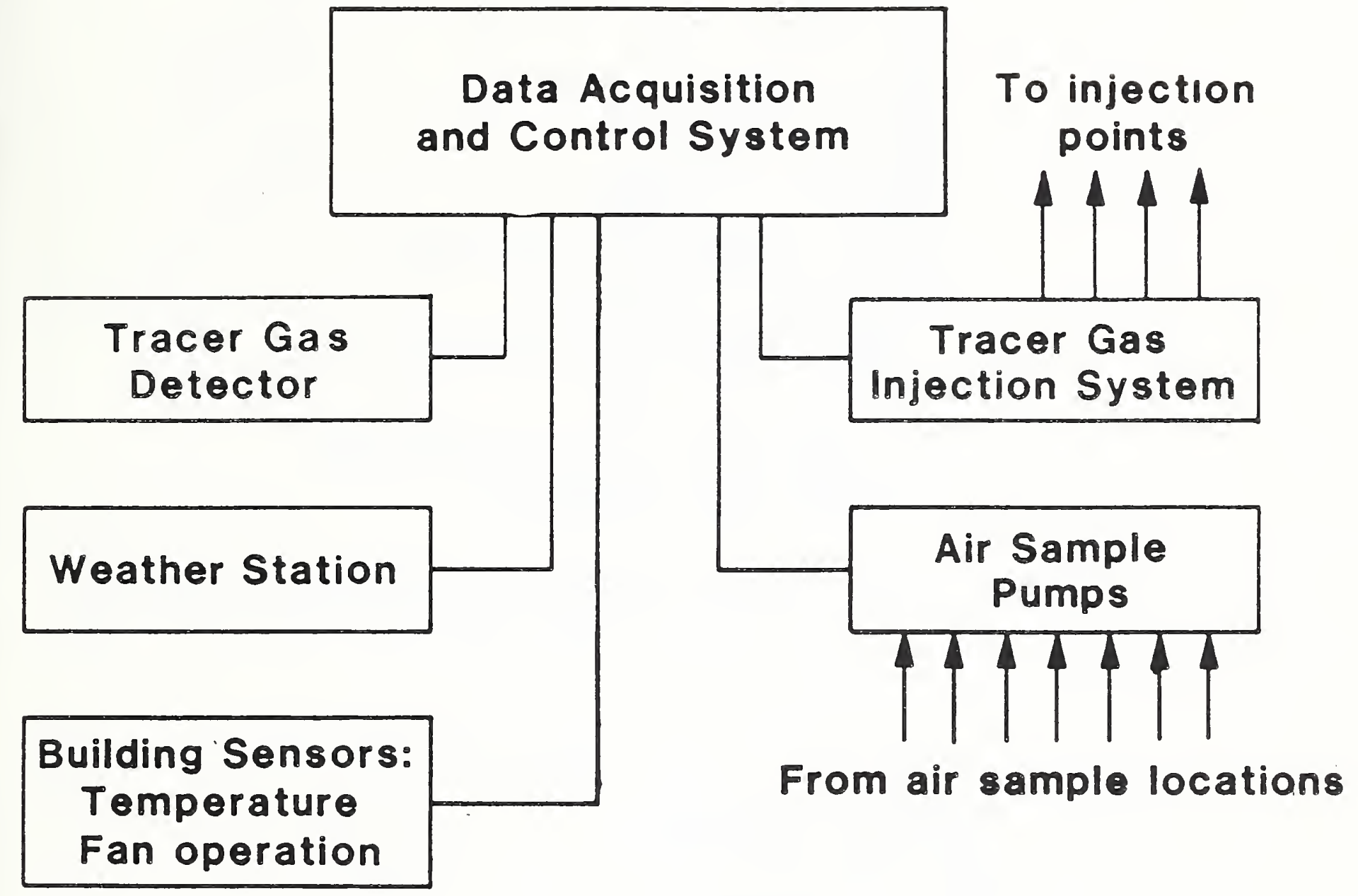

Figure 1 Schematic of a General Tracer Gas Measurement System 


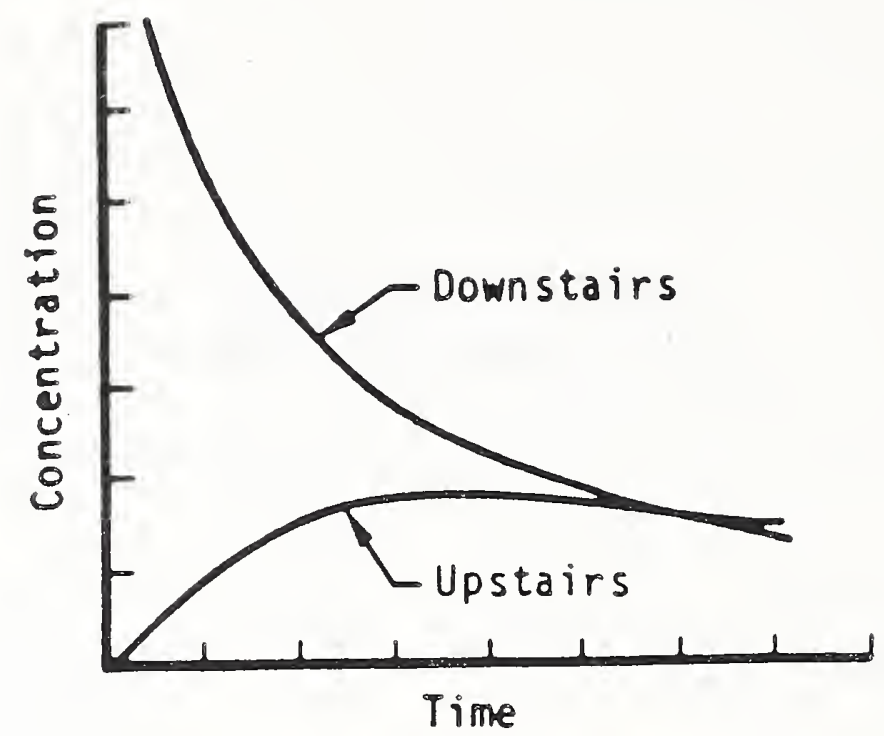

Concentration of $\mathrm{C}_{2} \mathrm{Cl}_{2} \mathrm{~F}_{4}$ against time, upstairs and downstairs

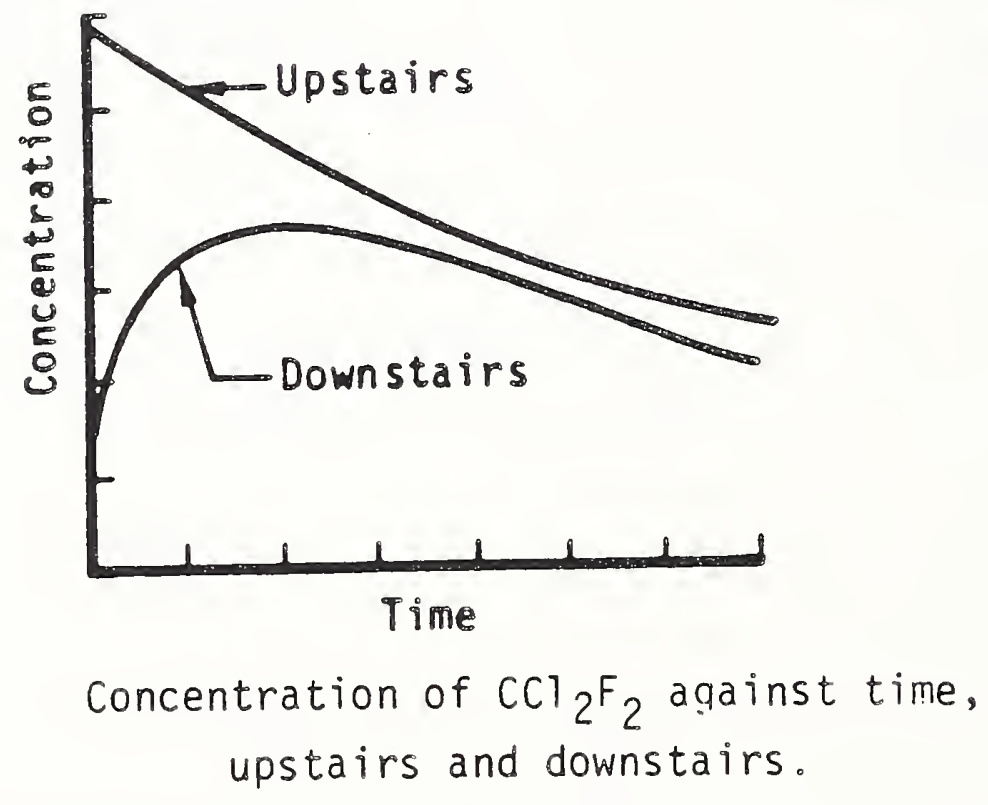

Figure 2 Representarive Two Tracer Data (I'Anson et al 1982) 

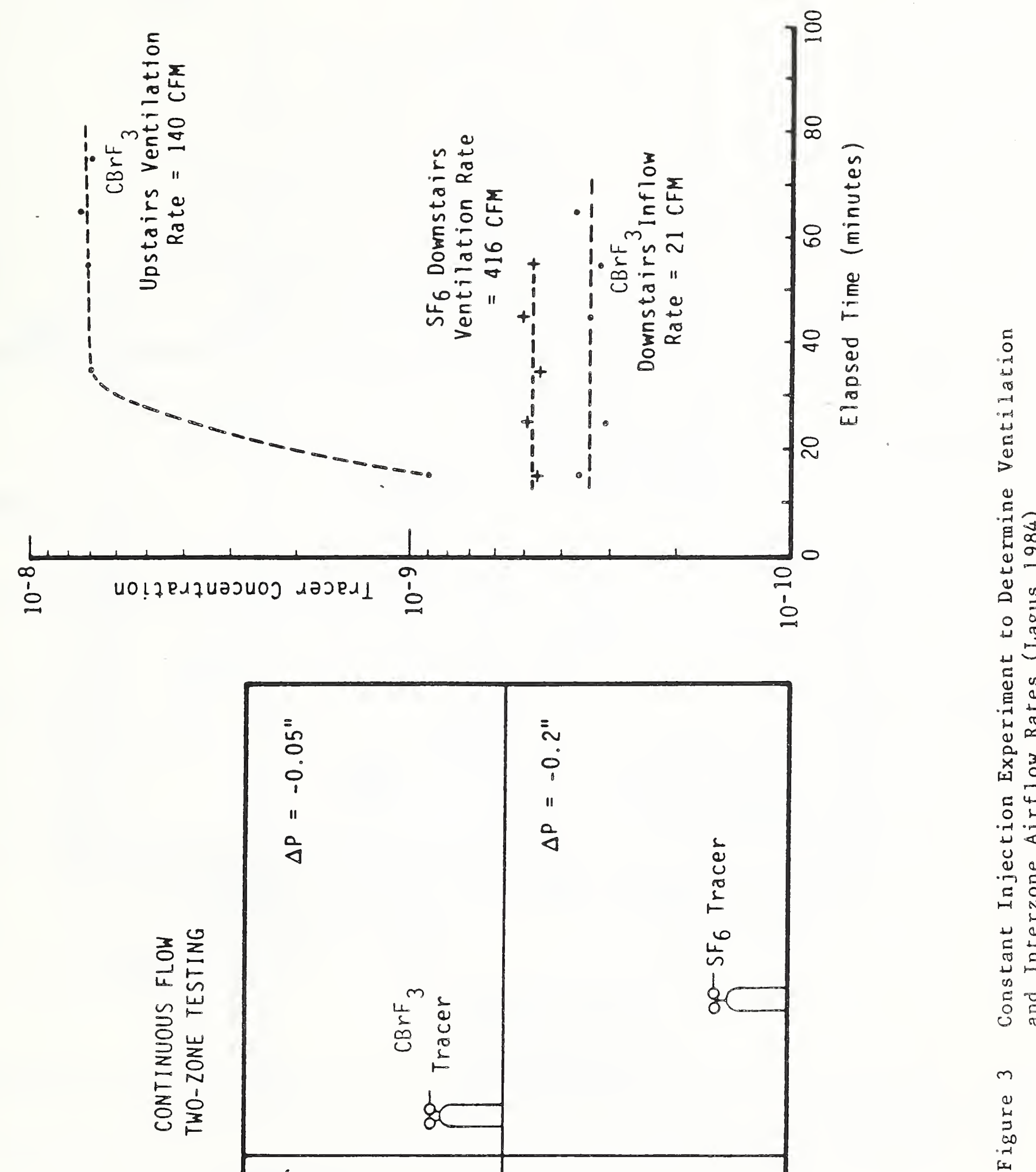


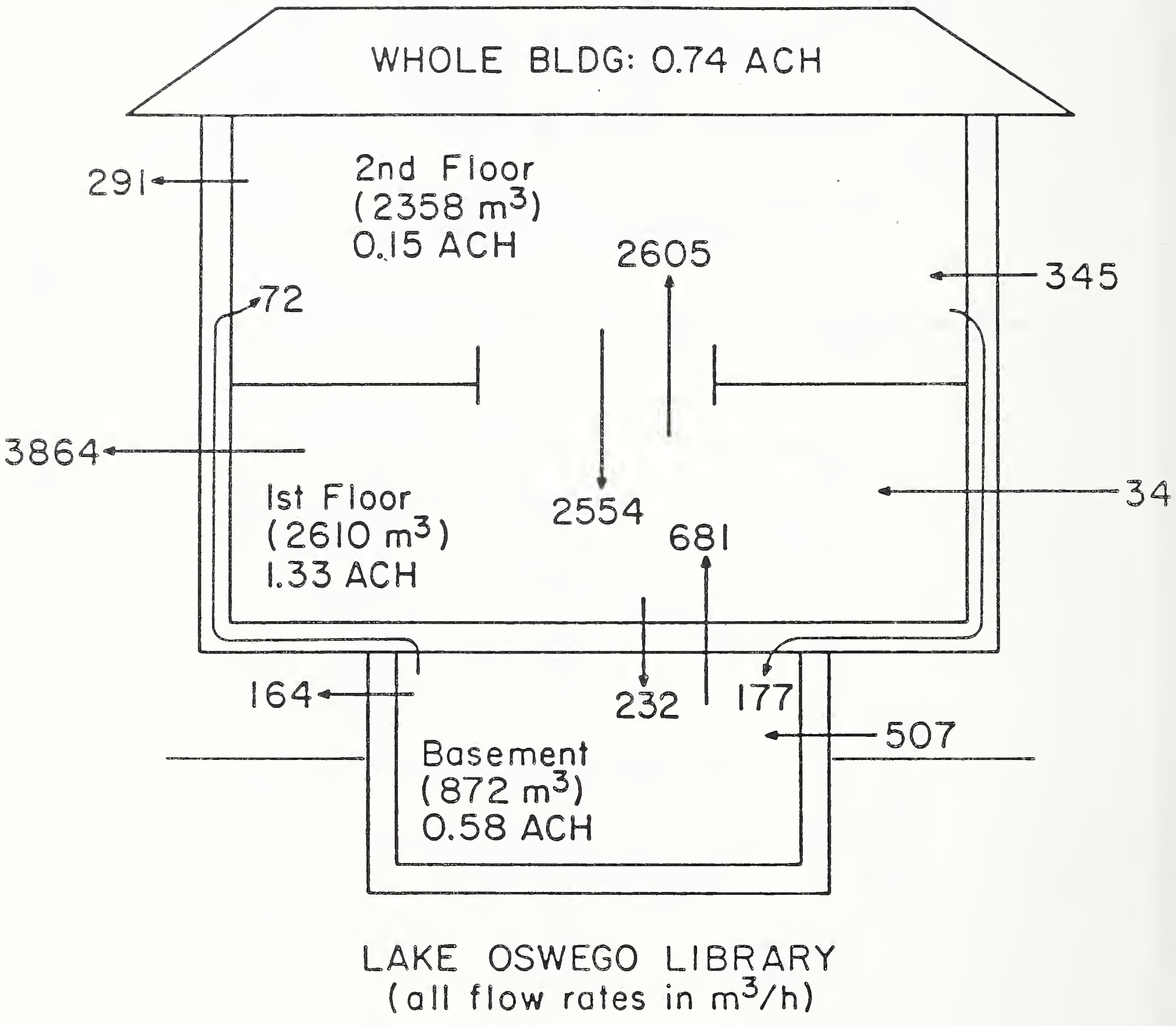

Figure 4 Airflow Rares Measured in Multi-Tracer Tests (Dietz et al 1984a) 


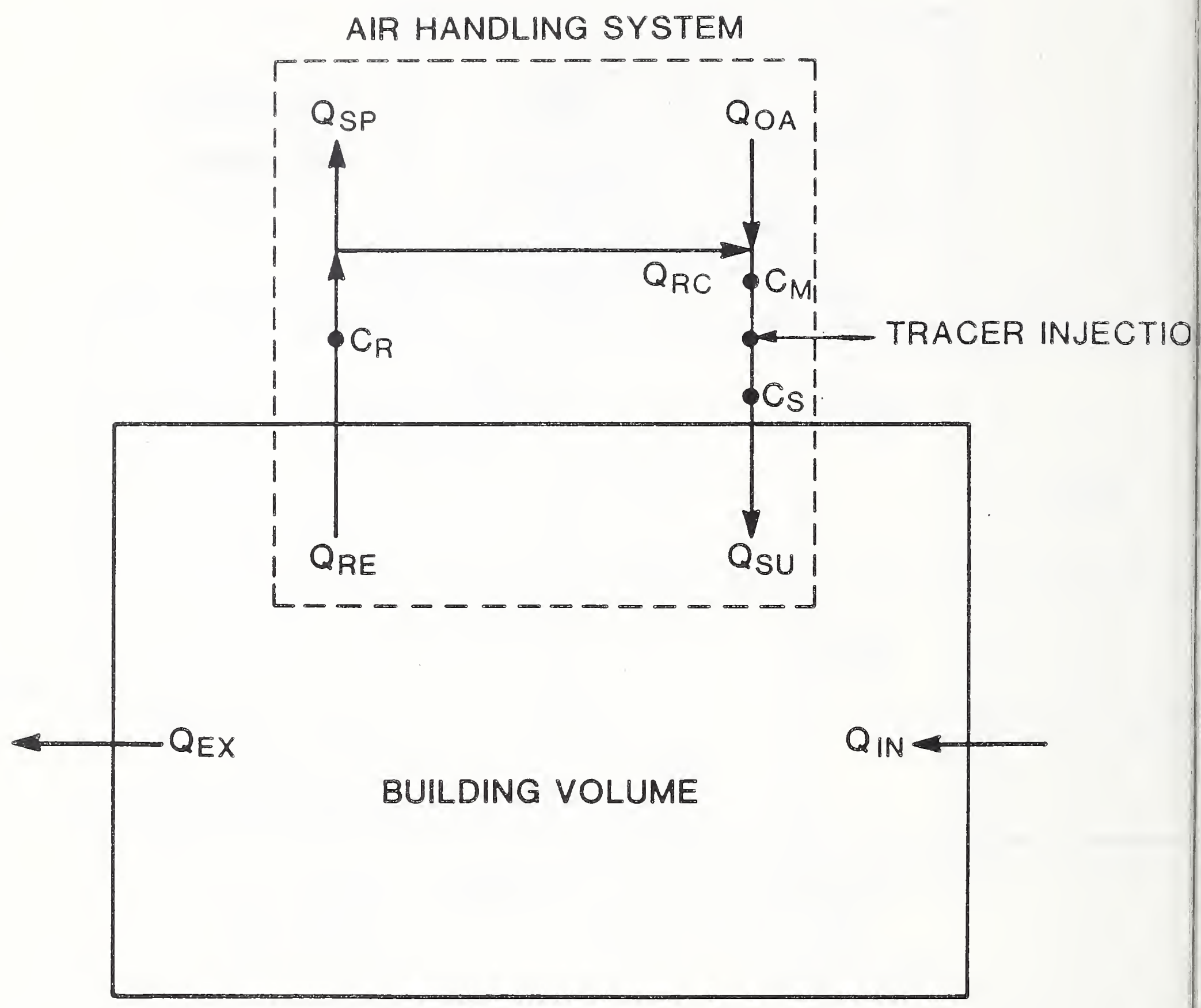

Figure 6 Schematic of Ventilation Airflow Rate Measurement Procedcures 


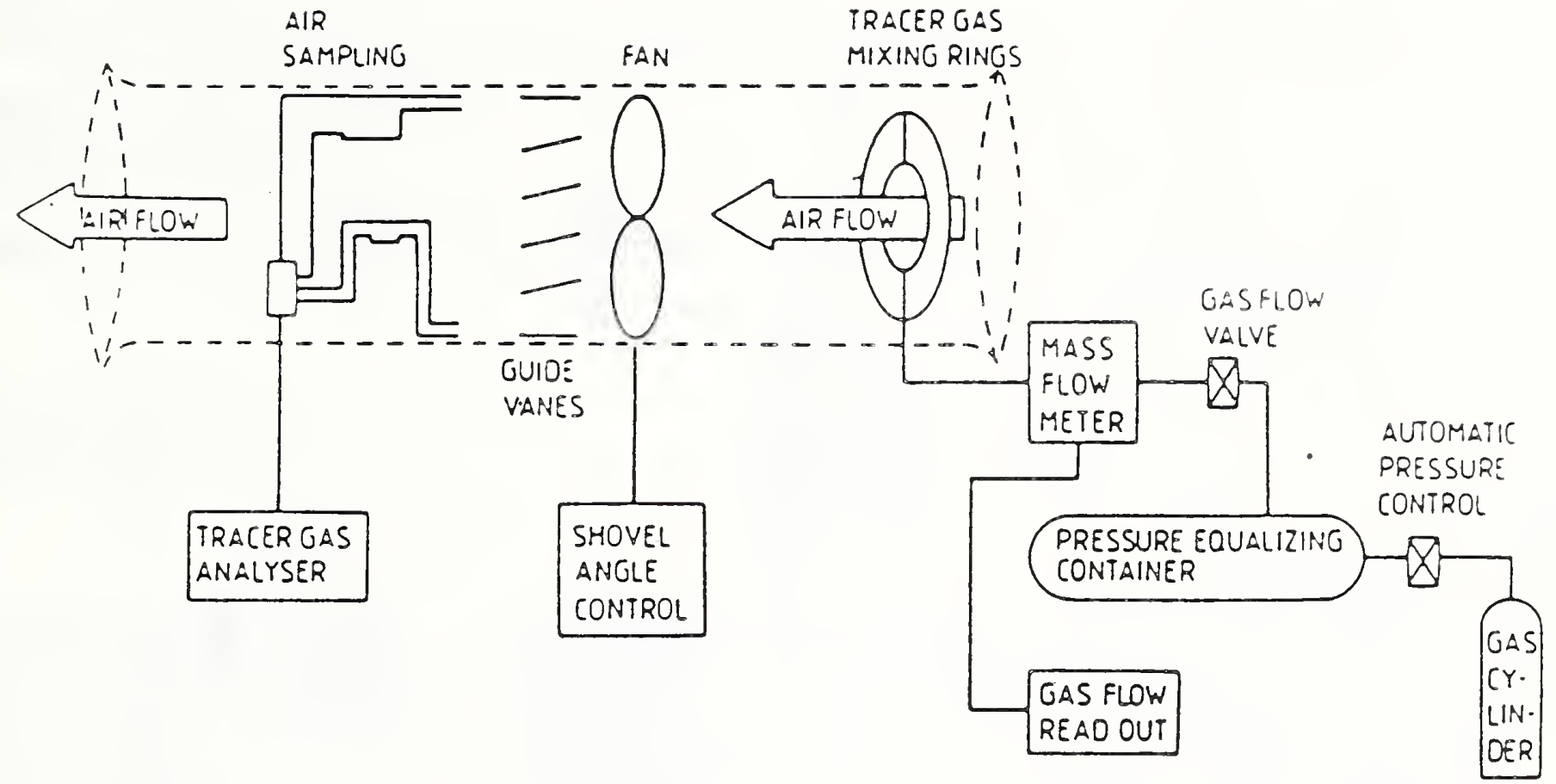

Figure 7 Schematic of Constant Injection Airflow Measurement System (Lund in 1984) 


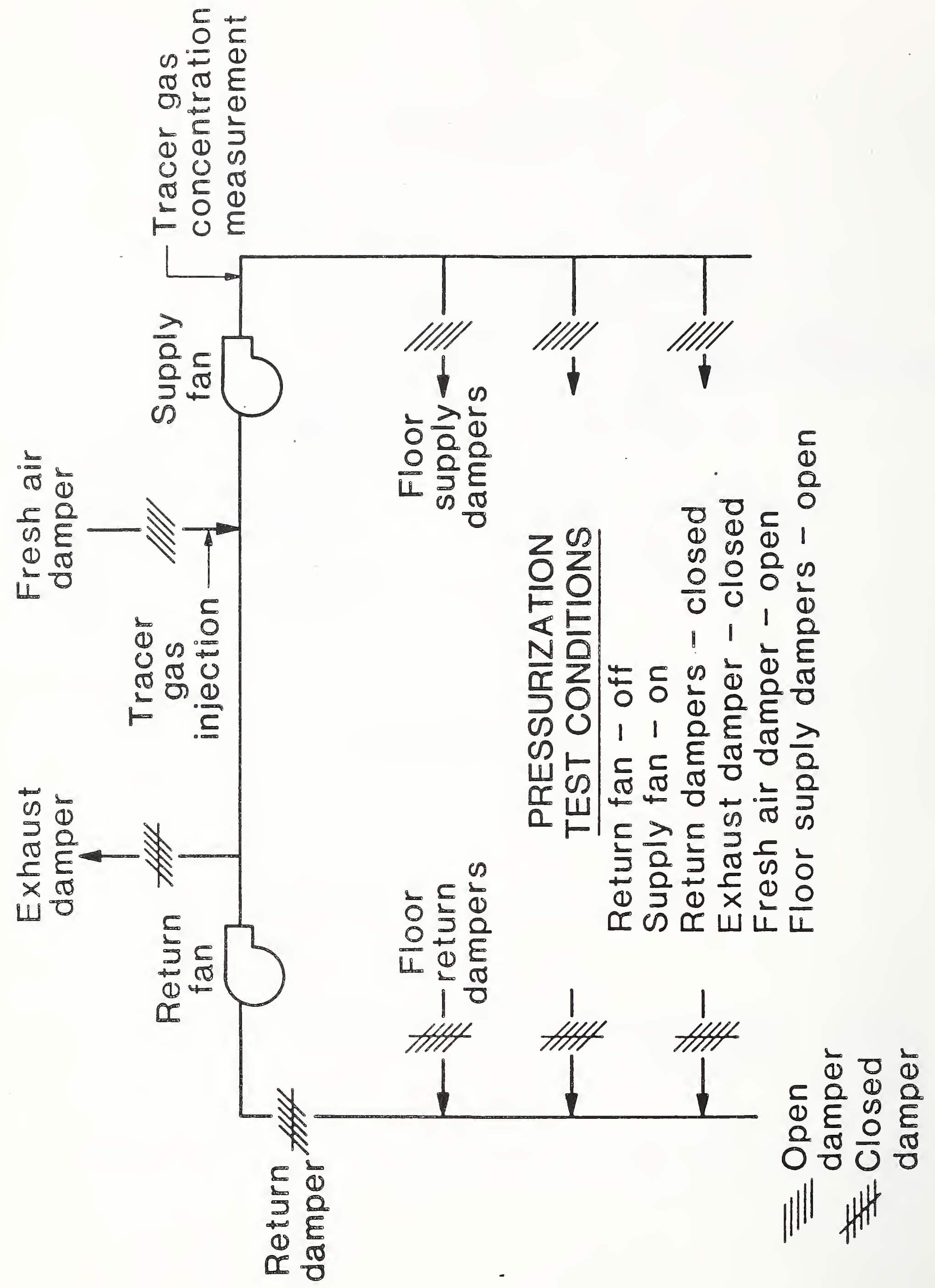


NBS-114A (REV. 2-8C)

\begin{tabular}{|c|c|c|c|}
\hline $\begin{array}{l}\text { U.S. DEPT. OF COMM. } \\
\text { BIBLIOGRAPHIC DATA } \\
\text { SHEET (See in structions) }\end{array}$ & $\begin{array}{l}\text { 1. PUBLICATION OR } \\
\text { REPORT NO. } \\
\text { NBSIR } 88-3708\end{array}$ & 2. Performing Organ. Report No. & $\begin{array}{l}\text { 3. Publication Date } \\
\text { FEBRUARY } 1988\end{array}$ \\
\hline
\end{tabular}

4. TITLE AND SUBTITLE

Tracer Gas Techniques for Studying Building Air Exchange

5. $A \cup T H O R(S)$

Andrew Persily

6. PERFORMING ORGANIZATION (If joint or other than NBS, see instructions) $\quad$ 7. Coneract/Grant No.

NATIONAL BUREAU OF STANDARDS

DEPARTMENT OF COMMERCE

WASHINGTON, D.C. 20234

9. SPONSORING ORGANIZATION NAME AND COMPLETE ADDRESS (Street. City, Stote, ZIP)

8. Type of Report \& Period Covered

National Bureau of Standards

10. SUPPLEMENTARY NOTES

Document describes a computer program; SF-185. FIPS Software Summary, is attached.

11. ABSTRACT (A 200-word or less factual summary of most significant information. If document includes a significant bibliography or literoture survey. mention it here)

A variety of procedures have been developed that employ tracer gases to examine the air exchange characteristics of buildings. These procedures enable the examination of several features of building air exchange including ventilation rates, air movement within buildings, and building envelope airtightness. This paper reviews tracer gas measurement techniques that have been used to study air exchange in buildings. Background information is discussed such as the instrumentation used in these tests, building features that influence their application, and the fundamental theory of tracer gas measurement. Several specific applications are discussed including air exchange rate measurement in large buildings, low-cost procedures for measuring air exchange rates in large numbers of buildings, techniques for evaluating the performance of air distribution systems, and pressurization testing of envelope airtightness in large buildings. A detailed bibliography is also included to facilitate a more thorough examination of the topics discussed.

12. KEY WORDS (Six to iwelve entries: alphabetical order: capitalize only proper names; ond separate key words by semicolons) airflow measurement; building performance; infiltration; measurement; tracer gas; ventilation.

13. AVAILABILITY

[X] Unlimited

E For Official Distribution. Do Not Release to NTIS

Order From Superintendent of Documents, U.S. Government Printing Office, Washington, D.C. 20402.

X Order From National Technical Information Service (N.TIS). Springfield, VA. 2216I

14. NO. OF PRINTED PAGES

\section{8}

15. Price

$\$ 11.95$ 

。

- 